\title{
Pancreatitis aguda necrotizante en una intoxicación fatal por metadona.
}

Acute necrotizing pancreatitis in a fatal poisoning with methadone.

A.Sibón y cols.

Cuad Med Forense 2004;35:31-36

Se trata de un caso de muerte con pancreatitis aguda necrotizante y hemorrágica, hemorragia suprarrenal y edema pulmonar en el contexto de una sobredosis por metadona en un paciente en programa de mantenimiento, varón de 24 años, adicto a la heroína en los 4 años previos. Realizó una sobreingesta intencionada con fines autolíticos.

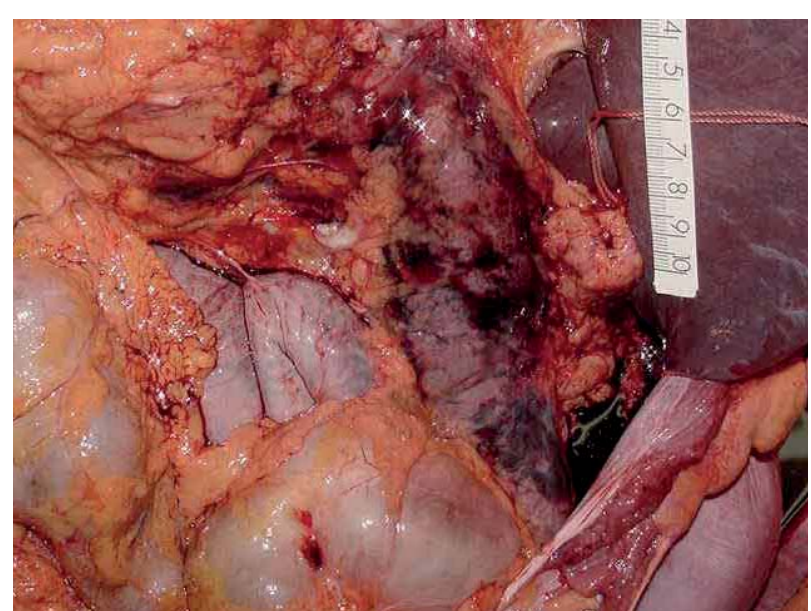

Figura 1.- Fotografía de la transcavidad de los epiplones. Se aprecia la cara anterior del páncreas con grandes zonas de hemorragia bajo la fascia.

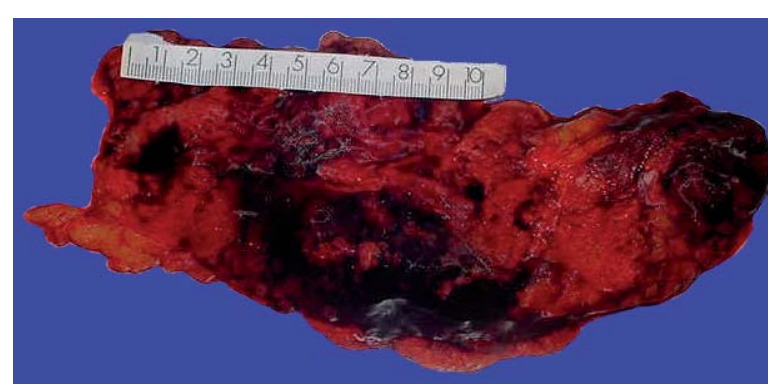

Figura 2.- Zonas de necrosis y hemorragia en el parénquima pancreático. 


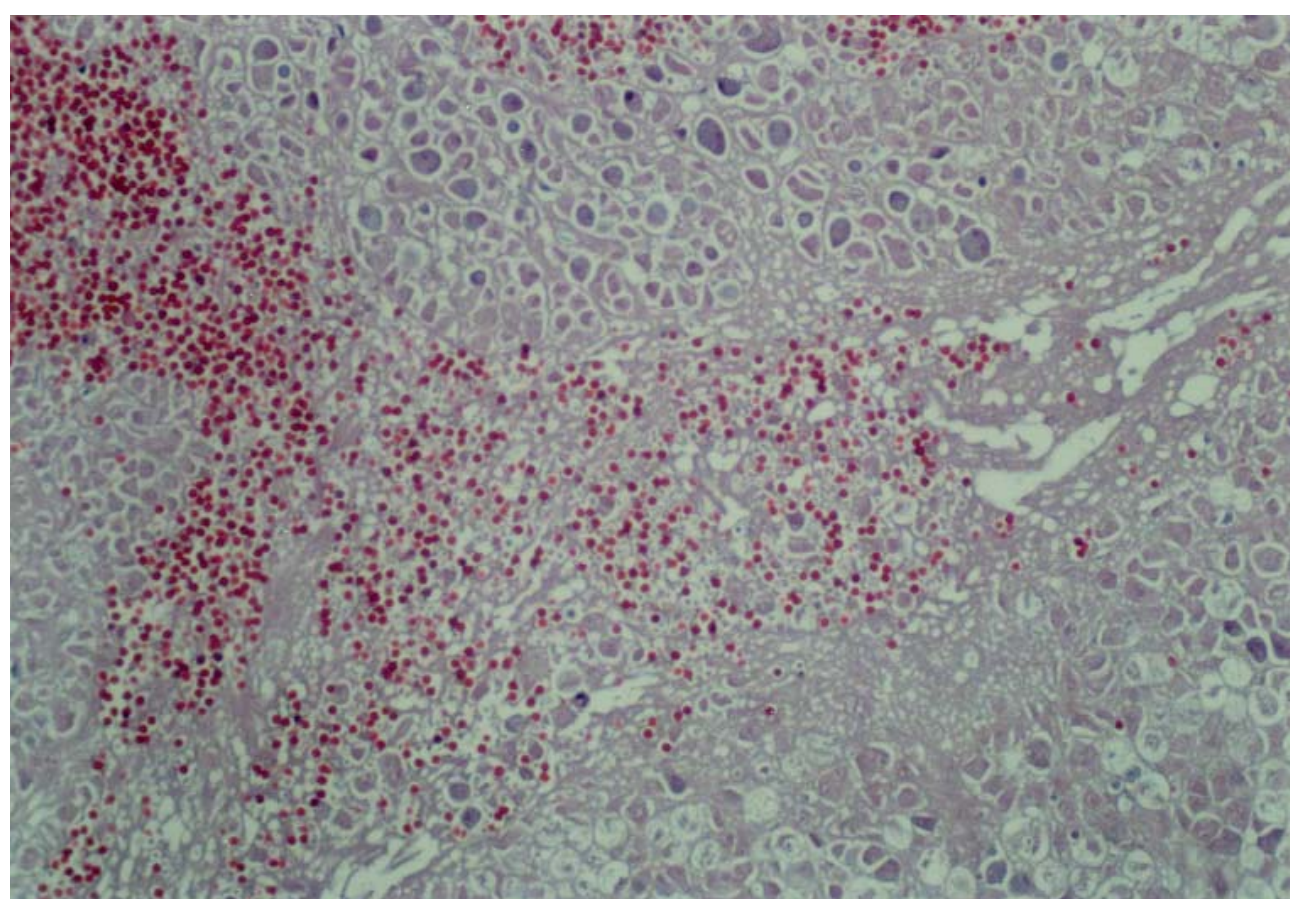

Figura 3.- Necrosis del tejido pancreático que afecta a los tejidos acinar y ductal, y se asocia a hemorragia intraparenquimatosa (20X HE).

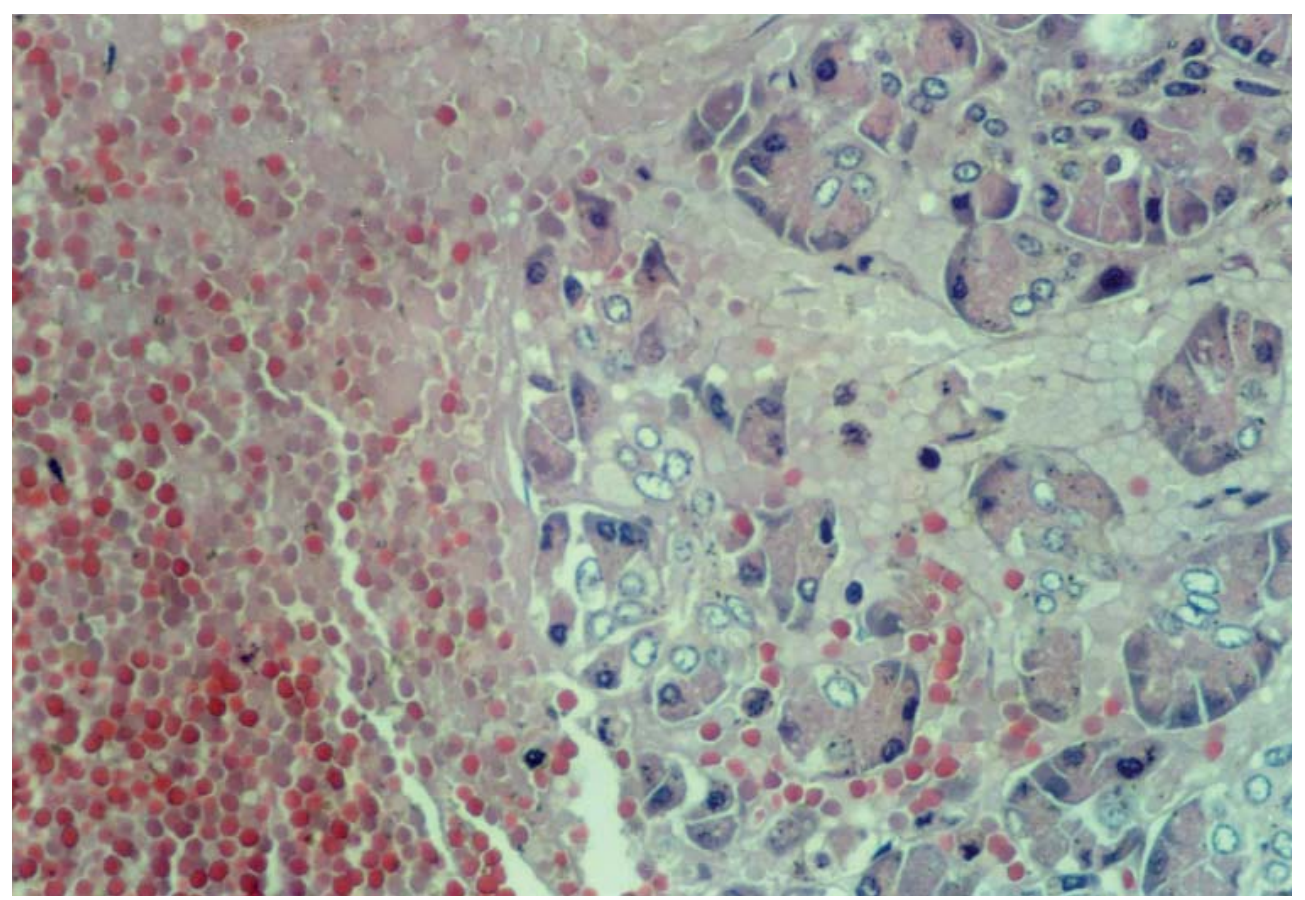

Figura 4.- A mayor aumento, se observa la necrosis de las células acinares y la profusa hemorragia acompañante (40X HE). 